\title{
Concise Research Report: The Future of Medicaid: State Legislator Views on Policy Waivers
}

\author{
Jane M. Zhu, MD, MPP ${ }^{1,2}$, Manik Chhabra, $M^{1,2}$, and David Grande, MD, MPA ${ }^{1,2}$ \\ 'Division of General Internal Medicine, University of Pennsylvania Perelman School of Medicine, Philadelphia, PA, USA; ${ }^{2}$ Leonard Davis Institute of \\ Health Economics, University of Pennsylvania, Philadelphia, PA, USA.
}

KEY WORDS: medicaid; health reform; health insurance; state health policy.

J Gen Intern Med 33(7):999-1001

DOI: $10.1007 / \mathrm{s} 11606-018-4432-8$

() Society of General Internal Medicine 2018

\section{INTRODUCTION}

As the Medicaid program is defined increasingly at the state level, state legislators will have growing influence on the direction of a program that now covers 72.4 million low-income adults and children. ${ }^{1}$ While Medicaid's federal-state partnership structure has long permitted states to adopt modifications to coverage design, the Trump administration has made it easier for states to receive Medicaid waivers, ${ }^{2}$ including fast-track approvals and longer demonstration approval periods. The combination of greater state flexibility and reductions in overall funding could produce substantial shifts in state Medicaid policy; the recent approval of Kentucky's Section 1115 waiver, which included work eligibility requirements, may be a precursor to impending program changes rather than an outlier. Understanding state legislator views of the Medicaid program and proposed changes is therefore critical to addressing future policy directions.

\section{METHODS}

Using the National Conference of State Legislators (NCSL) database, we surveyed state legislators $(n=7340)$ on their priorities for Medicaid reform and perspectives on specific policy changes. We evaluated policies selected from approved and pending Medicaid section 1115 waiver applications. ${ }^{3}$ The survey instrument was pilot-tested with current state legislators and federal legislative staff to ensure policy relevance of questions and non-partisan language. We contacted all legislators by email up to three times and a randomly sampled subset of non-responders by phone. The survey was administered through Research Electronic Data Capture (REDCap version 7.2.2, Vanderbilt University). Descriptive analyses were

Published online May 15, 2018 conducted to characterize how views differed by political party. The Institutional Review Board at the University of Pennsylvania approved this study.

\section{RESULTS}

Overall, 894 (12.2\%) state legislators completed the survey, a response rate consistent with those in other studies of elitelevel actors. ${ }^{4}$ Non-respondents were more likely to be nonhealth care committee members, Republican, male, and from the Midwest region.

Compared to their Democratic colleagues, more Republicans selected reducing health care spending ( 85.2 vs. $68.8 \%$ ) and limiting the role of the federal government ( 74.1 vs. $6.0 \%$ ) as a high priority (Fig. 1). In comparison, Democrats emphasized expanding access to care (97.2 vs. 18.8\%) and narrowing disparities (95.7 vs. 40.9\%). Republicans and Democrats agreed on a single goal-increasing the affordability of health care (84.4 and $99.2 \%$, respectively).

The majority of Republicans supported linking Medicaid eligibility to work requirements for able-bodied adults (Fig. 2, 84.8 vs. $26.7 \%$ Democrats) and drug-testing beneficiaries (62.8 vs 3.8\% Democrats). Republicans were also more likely to support increasing cost-sharing for Medicaid recipients ( 70.9 vs. $12.7 \%$ ), shifting Medicaid-eligible individuals to private insurance using premium support (64.0 vs. 9.7\%), mandatory health savings accounts with minimum monthly contributions (60.4 vs. 9.1\%); and introducing financial incentives or disincentives for health-related behaviors (55.2 vs. $23.8 \%, p<0.0001$ for all comparisons).

Half of Republicans and $60.1 \%$ of Democrats supported a tiered benefit structure such that lower-income Medicaid recipients would pay less for benefits than others with relatively higher incomes. Nearly two thirds (60.2\%) of Republicans and $85.8 \%$ of Democrats favored policies to reduce the prices paid for drugs. Few legislators supported shifting some Medicaid funding towards addressing social determinants of health, such as housing (15.1\% of Republicans vs. $14.2 \%$ of Democrats). Finally, neither Republicans nor Democrats supported capping enrollment (19.1 and 1.3\%, respectively) reducing services and benefits (34.4 and 1.7\%), or reducing the income eligibility threshold for Medicaid beneficiaries (39.4 and 3.7\%). 


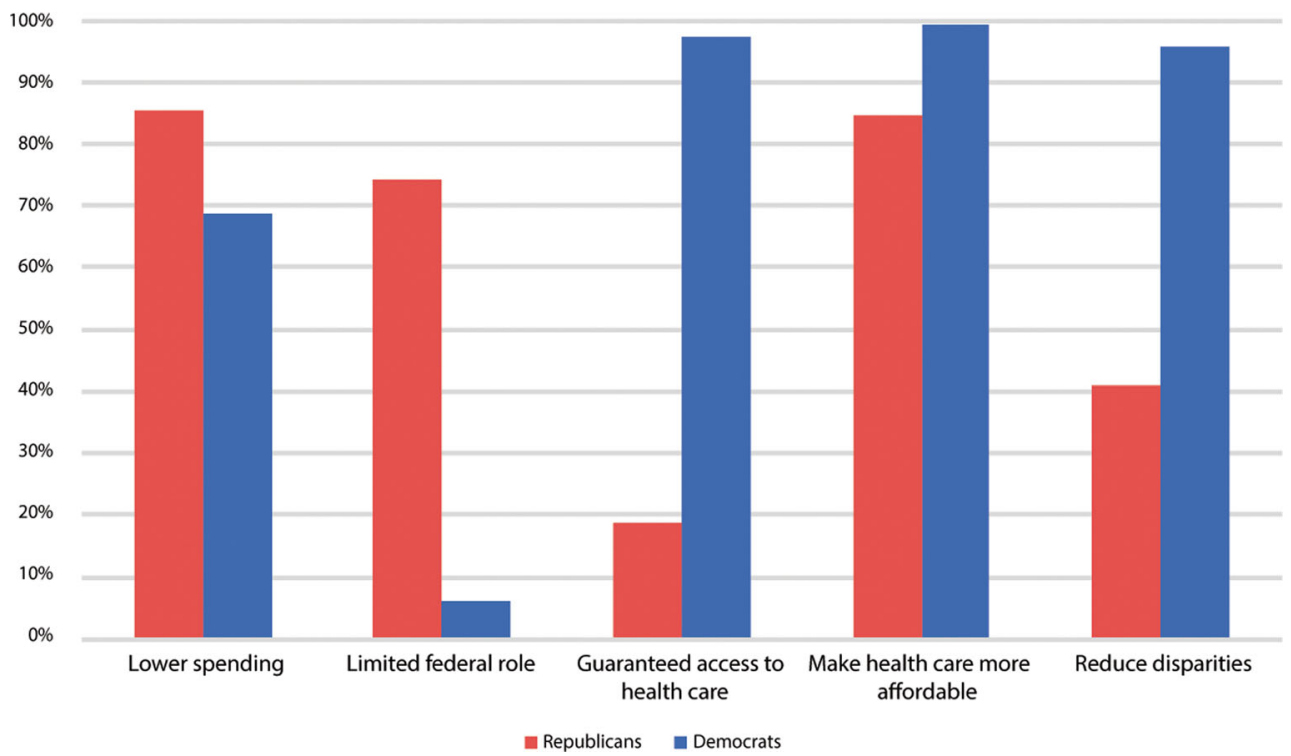

Figure 1. State legislators' support for Medicaid reform goals. Authors' survey of state legislators using the National Conference of State Legislators database. Figure 1 shows, by party, the level of support for each of five health reform goals. The vertical axis represents the percentage of state legislators who supported or strongly supported each goal, as shown on the horizontal axis.

\section{DISCUSSION}

As states gain more autonomy to design their own Medicaid programs, a key question is whether waiver provisions and other changes will further Medicaid's overall objective to provide medical coverage for low-income and disabled populations. ${ }^{5}$ While limited by the potential for nonresponse bias, our findings suggest partisan uptake of policy proposals, like work eligibility requirements and drug testing Medicaid recipients, that extends beyond the few states with pending Section 1115 demonstration waivers featuring these provisions. Taken together, stark differences across political parties could translate into major changes in the design of Medicaid programs across the country, depending on the balance of power within each state's branches of government. As states pursue and implement changes to Medicaid policy, there is a critical need to evaluate the impact on access to care and health outcomes for the Medicaid population.

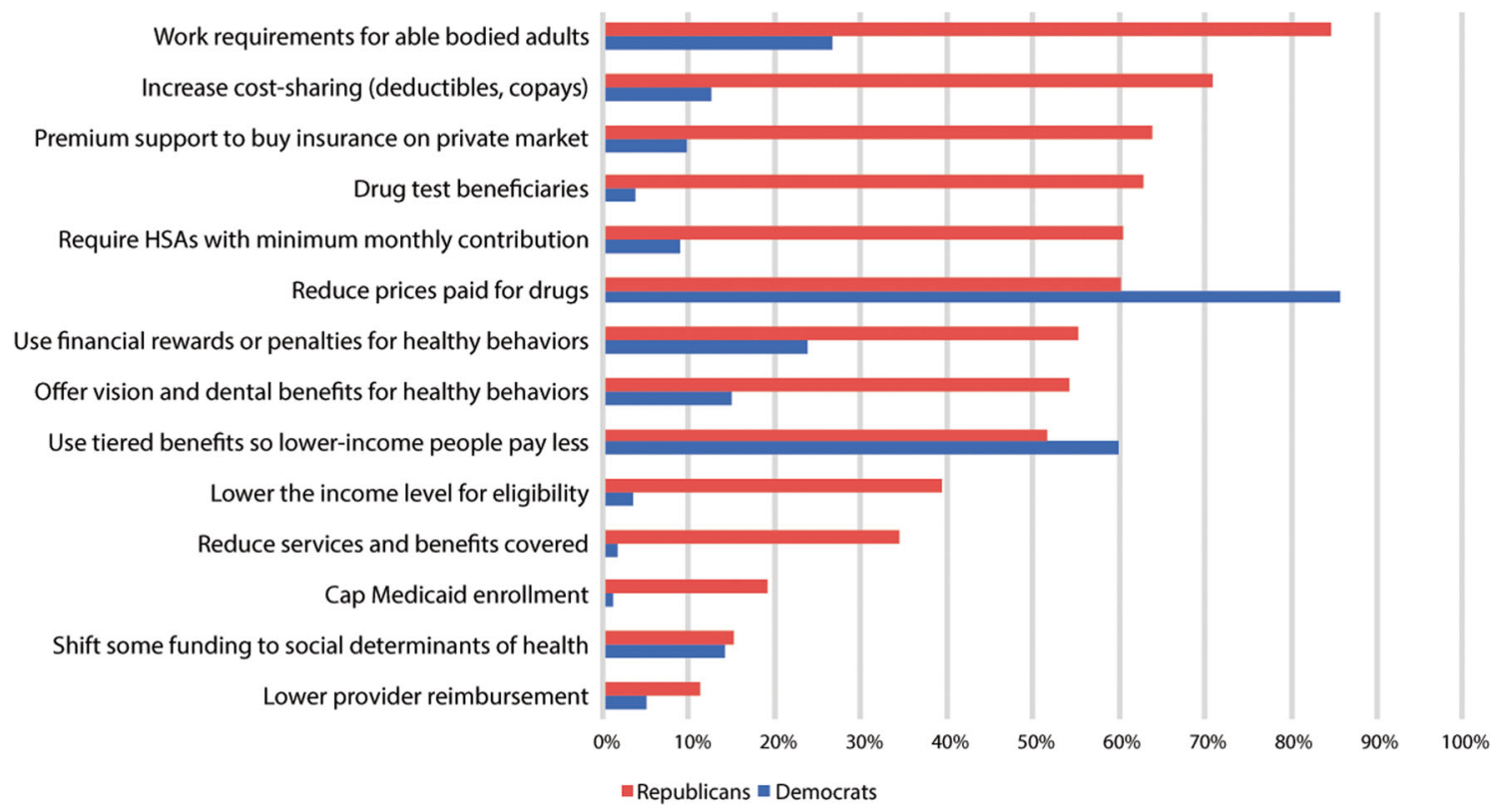

Figure 2. State legislators' support for Medicaid policy changes. Authors' survey of state legislators using the National Conference of State Legislators database. Figure 2 shows the percentage of state legislators, by political party, who support or strongly support various Medicaid reform proposals. 
Acknowledgements: We would like to thank David Asch, Janet Weiner, and Rebecka Rosenquist for their review of prior drafts, Kira Flemke for administrative and logistical contributions, and Christopher M. Aderman for graphics assistance.

Corresponding Author: Jane M. Zhu, MD, MPP; Division of General Internal Medicine University of Pennsylvania Perelman School of Medicine, Philadelphia, PA, USA (e-mail: zhuja@pennmedicine. upenn.edu).

Funding Information This study was funded by the Leonard Davis Institute of Health Economics at the University of Pennsylvania.

\section{Compliance with Ethical Standards:}

Conflict of Interest: The authors declare that they do not have a conflict of interest.

\section{REFERENCES}

1. Keehan SP, Stone DA, Poisal JA, et al. National health expenditure projections, 2016-25: price increases, aging push sector to 20 percent of economy. Health Aff Proj Hope 2017;36:553-63.

2. Price TE, Verma S. Secretary price and CMS administrator verma letter [Internet]. 2017. Accessed 21 Mar 2018. Available from: https://www.hhs. gov/sites/default/files/sec-price-admin-verma-ltr.pdf.

3. Musumeci MB, Hinton E, Rudowitz R. Section 1115 medicaid expansion waivers: a look at key themes and state specific waiver provisions [Internet]. Menlo Park, CA and Washington, DC: Kaiser Family Foundation; 2017 Accessed 21 Mar 2018. Available from: http://files.kff.org/ attachment/Issue-Brief-Section-1115-Medicaid-Expansion-Waivers-ALook-at-Key-Themes-and-State-Specific-Waiver-Provisions.

4. Pagel C, Bates DW, Goldmann D, Koller CF. A way forward for bipartisan health reform? democrat and republican state legislator priorities for the goals of health policy. Am J Public Health 2017;107(10):1061-3.

5. Compilation of the Social Security Laws. Sec. 1901. [42 U.S.C. 1396] [Internet]. Accessed 21 Mar 2018. Available from: https://www.ssa.gov/ OP_Home/ssact/title19/1901.htm. 